ORIGINAL ARTICLE

\title{
Short term and long term detraining: is there any difference between young-old and old people?
}

N F Toraman

Br J Sports Med 2005;39:561-564. doi: 10.1136/bjsm.2004.015420

See end of article for authors' affiliations .....................

Correspondence to: Dr Toraman, Department of Health Sciences, Akdeniz Univesity School of Physical Education and Sports, Antalya 07058, Turkey; ftoraman@ akdeniz.edu.tr

Accepted 10 November 2004

\begin{abstract}
Objectives: To assess the effects of short (six weeks) and long (52 weeks) term detraining on functional fitness in elderly people, and to determine whether these effects differ according to age in elderly people. Methods: Elderly subjects, aged 60-86 years, completed a nine week multicomponent exercise training programme. They performed the senior fitness test after six and 52 weeks, and the responses of 12 youngold subjects (YO, aged 60-73 years) and nine older subjects $(\mathrm{O}$, aged 74-86 years) were compared. Results: Functional fitness improved during the exercise training period. Short term detraining caused a loss of this improvement in functional performance. Performance on the chair stand test for both $\mathrm{YO}$ and $\mathrm{O}$ groups and on the up and go and six minute walk tests for the $Y O$ group remained significantly higher than before training after six weeks of detraining $(p<0.013)$. Performance in all tests reverted to the pretraining values or lower after 52 weeks of detraining in both groups. In the $O$ group, performances in the six minute walk test and arm curl test were lower than before training $(p<0.013)$. The components of functional fitness most affected by detraining were agility with short term detraining, and aerobic endurance and upper extremity strength with long term detraining.

Conclusion: Changes in functional capacity after short and long term detraining are affected by age in elderly adults.
\end{abstract}

$\mathrm{R}$ egular exercise has many health benefits and can prevent certain diseases. ${ }^{12}$ However, to retain these benefits, one must remain physically active throughout life. Because of chronic disease, stays in hospital, or the side effects of drugs, elderly people are more prone to interruptions in their exercise programmes than are younger adults.

Detraining occurs after the cessation of training, when previous adaptations are gradually lost. ${ }^{3}$ Most studies of detraining in elderly people have focused on the effects on muscular strength, ${ }^{4-14}$ performance measures of physical function, ${ }^{8}{ }^{11}$ body composition, ${ }^{6}$ and blood lipid concentration. ${ }^{12}$ In these studies, detraining generally follows moderate to high intensity resistance training, ${ }^{4-14}$ and few studies have focused on the effects of detraining after cardiovascular exercise training. ${ }^{4}$

To my knowledge, no studies have compared the effects of short and long term detraining on functional fitness, nor have any determined whether such effects differ with age in elderly people. Functional fitness is defined as having the physiological capacity to perform normal everyday activities safely and independently without undue fatigue. ${ }^{15}$

In the laboratory, we compared the responses of young-old (YO, aged 60-73 years) and older ( $\mathrm{O}$, aged 74-86 years) subjects to a standardised multicomponent exercise training programme and subsequent period of detraining to determine whether regular physical activity influences the age related changes in functional fitness during detraining. The aims were to determine the effects of short (six weeks) and long ( 52 weeks) term detraining on functional fitness in the $\mathrm{YO}$ and $\mathrm{O}$ groups, which component of functional fitness was most affected by short and long term detraining, and whether functional fitness responded differently to detraining in the two groups.

\section{METHODS}

Participants

Forty two elderly adults were initially recruited to take part in a randomised trial designed to investigate the effects of a nine week exercise training programme on functional fitness and body composition ${ }^{16}$ and the responses to the multicomponent training. ${ }^{17}$ Subjects were volunteers who were older than 60 years, healthy, and without serious cardiovascular or musculoskeletal diseases, living independently in a retirement home, performing activities of daily living without mobility aids, and had a standardised mini-mental state examination score $\geqslant 20$. All participants had medical clearance to participate in the testing and training sessions.Twenty two subjects were assigned to the YO group (aged 60-73 years) and 20 to the O group (aged 74-86 years). The $\mathrm{YO}$ and $\mathrm{O}$ groups were randomly subdivided into exercisers and control subjects, who did not exercise. Twelve of the YO group participated in the exercise programme and 10 served as non-exercise control subjects; nine of the O group exercised and 11 were controls.

The elderly subjects gave written informed consent before the study began and also before the detraining study. Of the 42 subjects in the initial phase of the study, 21 of the exercisers and four of the control subjects volunteered for the detraining study. Reasons for not participating in the detraining study were: relocation $(\mathrm{n}=4)$, lack of interest in the study $(\mathrm{n}=3)$, continuing the exercise programme $(n=4)$, diagnosis of cancer $(n=1)$, marriage $(n=1)$, fracture $(n=1)$, diagnosis of arthritis $(n=2)$, and recent myocardial infarction $(n=1)$. Because the aim was to study the effects of detraining after a training programme, we analysed only the values for the exercise group. During the detraining period, subjects were asked to maintain their normal levels of informal daily activity.

\section{Intervention}

The first phase of the study has been described in detail elsewhere. ${ }^{16}{ }^{17}$ Briefly, participants performed aerobic, resistance, and flexibility exercise training under the direct supervision of a research assistant. The training variables in the first week's aerobic training were: intensity, 50\% of heart rate reserve; duration, 20 minutes per session; and frequency, 
Table 1 Changes in functional fitness after training and detraining in two groups of elderly subjects

\begin{tabular}{|c|c|c|c|c|c|c|c|c|}
\hline \multirow[b]{3}{*}{ Test } & \multicolumn{4}{|c|}{ Young-old group ( $n=12$ ) } & \multicolumn{4}{|c|}{ Old group $(\mathrm{n}=9$ ) } \\
\hline & \multicolumn{2}{|l|}{ Training } & \multicolumn{2}{|l|}{ Detraining } & \multicolumn{2}{|l|}{ Training } & \multicolumn{2}{|l|}{ Detraining } \\
\hline & Pre- & Post- & 6 weeks & 52 weeks & $\overline{\text { Pre- }}$ & Post- & 6 weeks & 52 weeks \\
\hline $\begin{array}{l}8 \text { foot up } \\
\text { and go (s) }\end{array}$ & $6.3(1.3)$ & $4.6(0.8) \dagger$ & $5.4(0.7) \dagger \ddagger$ & $6.6(1.6) \ddagger$ & $7.2(1.5)$ & $5.2(1) \dagger$ & 6.5 (0.9) & $7.1(1.5) \ddagger$ \\
\hline $\begin{array}{l}\text { Chair stand } \\
\text { (rep) }\end{array}$ & $10.0(1.3)$ & $19.5(4.9) \dagger$ & $15.7(2.6) t \ddagger$ & $11.2(1.8) \neq \S$ & $10.6(2)$ & $18.1(3.5) \dagger$ & $13.2(1.9) t \ddagger$ & $10(1.5) \pm \S$ \\
\hline Arm curl (rep) & $17.3(1.7)$ & $22.8(3.6) t$ & $19.9(2.4) \ddagger$ & $15.8(3.5) \ddagger \S$ & $17.4(3.5)$ & $22.1(2.6) \dagger$ & $18.1(1.7) \ddagger$ & $12.3(2.1) \dagger \ddagger \S$ \\
\hline $\begin{array}{l}\text { Six minute walk } \\
\text { (m) }\end{array}$ & $482.8(53.6)$ & $567.2(56.8) \dagger$ & $543(54.9)+\ddagger$ & $432.9(72.1) \ddagger \S$ & $447(80.4)$ & $493.6(87.4) \dagger$ & $452.9(81.6) \ddagger$ & $349.5(67.6)^{*}+\ddagger$ \\
\hline $\begin{array}{l}\text { Chair sit and } \\
\text { reach }(\mathrm{cm})\end{array}$ & $-9.5(15.1)$ & $3.9(8.1) \dagger$ & $-4.7(10.2) \ddagger$ & $-8(11.4) \ddagger$ & $-21.1(5.4)$ & $-8.8(9.3) \dagger$ & $-16(7.2) \ddagger$ & $-18.9(8) \ddagger$ \\
\hline Back scratch $(\mathrm{cm})$ & $-10.7(10.8)$ & $-5.8(8.6) \dagger$ & $-9.6(8.6) \ddagger$ & $-14.3(12.4) \ddagger$ & $-20.6(12.5)$ & $-15.9(11.7) \dagger$ & $-19.4(11.4) \ddagger$ & $-18.9(10.9) \ddagger$ \\
\hline \multicolumn{9}{|c|}{$\begin{array}{l}\text { Values are mean (SD). Young-old group, aged } 60-73 \text { years; old group, aged } 74-86 \text { years. } \\
* p<0.008 \text {, group effect, repeated measures analysis of variance. } \\
+ \text { Significant difference } v \text { baseline, } p<0.013 \text {. } \\
\text { tSignificant difference } v \text { post-training, } p<0.013 \text {. } \\
\S \text { Significant difference } 6 \text { weeks } v 52 \text { weeks detraining, } p<0.013 \text {. } \\
\text { rep, Number of repetitions. }\end{array}$} \\
\hline
\end{tabular}

three days a week. After the first week, the aerobic training duration was increased by five minutes and the intensity by $5 \%$ of heart rate reserve every two weeks. Dynamic resistance exercises were performed in a circuit, organised as a row of 10 resistance exercise stations. The resistance exercises included stair stepping, knee flexion, seated lower leg lift, arm raise, chair squat, biceps curl, toe raise, modified push up, abdominal crunch, and hip extension. In the first week, subjects performed a single set of eight repetitions of unloaded exercises; the number of repetitions increased to 12 in the second week and the number of sets increased to three in the third week. Resistance training began at $50 \%$ of the predicted one repetition maximum, and the load gradually increased to $80 \%$ of the predicted one repetition maximum. When the number of repetitions was increased, the weight remained constant. The flexibility programme included static stretching of the major muscle-tendon groups. Subjects stretched in the middle of the each set and after each session. There were no significant differences in functional fitness at baseline between the groups $(p>0.05)$. The nine week multicomponent training programme significantly increased performance on functional fitness tests in both the YO and O groups, and the rate of restoration of functional fitness items was similar in the two groups. ${ }^{17}$

\section{Measurements}

Both groups were tested on four occasions, before training (pre-training), after the nine weeks of training (posttraining), after six week of detraining, and after 52 weeks of detraining. On the test day, subjects first completed a 10 minute warm up led by an exercise instructor, and then completed the senior fitness test items, ${ }^{18}$ as validated by Rikli and Jones. ${ }^{15}$ The tests were administered in accordance with the protocols described. ${ }^{18}$

The senior fitness test consists of six assessment items. The chair stand test assesses lower body strength. Each subject completed two practice repetitions and one 30 second test trial. The score was the total number of stands executed correctly within 30 seconds. The arm curl test assesses upper body strength. Each subject completed two practice repetitions and one 30 second test trial. The score was the total number of hand weight curls through the full range of motion in 30 seconds. The chair sit and reach test assesses lower body flexibility. Each subject completed two practice trials and two test trials. The score was the best distance achieved between the extended fingers and the tip of the toe. The back scratch test assesses upper body flexibility. Each subject completed two practice trials and two test trials. The score was the best distance achieved between the extended middle fingers. The 8 foot up and go test assesses agility and dynamic balance. Each subject completed one practice trial and two test trials. The score was the shortest time to rise from a seated position, walk 8 feet, turn, and return to the seated position. The six minute walk test assesses aerobic endurance. Each subject completed one practice trial two days before the test and one test trial. The score was the total distance walked in six minutes along a $45.72 \mathrm{~m}$ rectangular course.

\section{Statistical analysis}

All data are presented as means (SD). Data were analysed using the SPSS software (SPSS, version 10.0). Student's $t$ test for independent samples was used to compare baseline values between the groups. Statistical analyses were performed using a two factor general linear model, incorporating a mixed design, with one between-subjects factor of group (two levels: $\mathrm{YO}$ and $\mathrm{O}$ ) and one within-subjects factor of time (four levels: pre-training, post-training, six weeks of detraining, and 52 weeks of detraining). All analyses were corrected for sphericity using the methods of Greenhouse and Geisser. ${ }^{18 a}$ The Bonferroni adjustment for multiple tests was used to set the significance criterion to 0.008 - that is, 0.05 divided by 6 .

Post hoc analyses were conducted using paired $t$ tests to examine within-group differences between baseline values and those after nine weeks of training, and after six weeks and 52 weeks of detraining. The Bonferroni correction was applied to set the significance criterion to 0.013 - that is, 0.05 divided by 4.

To estimate whether changes in the parameters were meaningful in a practical way, the standardised response means (mean changes divided by the SD) were measured to calculate effect size; an effect size of 0.2-0.49 was considered small, $0.5-0.79$ moderate, and 0.8 or greater, large. ${ }^{19}$

\section{RESULTS}

The mean ages of the subjects were 67.3 (4.2) years for the YO group (eight men, four women) and 79.6 (3.8) years for the $\mathrm{O}$ group (nine men) $\mathrm{p}<0.001)$. There were significant effects of time for the arm curl $\left(F_{2.52,47.95}=37.56, \mathrm{p}<0.001\right)$, the chair stand $\left(F_{1.55,29.46}=58.89, \mathrm{p}<0.001\right)$, the up and go $\left(F_{1.51,28.74}=20.94, \mathrm{p}<0.001\right)$, the chair sit and reach $\left(F_{2.44,46.43}=11.12, \mathrm{p}<0.001\right)$, and the six minute walk $\left(F_{1.83,34.69}=31.27, \mathrm{p}<0.001\right)$. The effect of time was not 


\begin{tabular}{|c|c|c|c|c|c|c|}
\hline \multirow[b]{3}{*}{ Test } & \multicolumn{6}{|c|}{ Effect size } \\
\hline & \multicolumn{2}{|c|}{ Within Y-O group } & \multicolumn{2}{|c|}{ Within 0 group } & \multicolumn{2}{|c|}{ Between groups } \\
\hline & 6 & 52 & 6 & 52 & 6 & 52 \\
\hline 8 foot up and go & 1.1 & 1.4 & 1.6 & 1.5 & 1.4 & 0.3 \\
\hline Chair stand & 1 & 1.7 & 2.3 & 3 & 1.1 & 0.7 \\
\hline Arm curl & 1 & 1.8 & 2 & 4.2 & 0.8 & 1.2 \\
\hline Six minute walk & 0.4 & 0.5 & 2.1 & 1.8 & 1.3 & 1.2 \\
\hline Chair sit and reach & 0.9 & 0.9 & 1.2 & 1.2 & 1.3 & 1.1 \\
\hline Back scratch & 0.4 & 0.3 & 0.8 & 0.3 & 1 & 0.4 \\
\hline
\end{tabular}

significant for the back scratch $\left(F_{1.22,23.16}=2.73, \mathrm{p}=\right.$ $0.106)$. Repeated measures analysis of variance showed a significant between-subject effect only for the six minute walk $\left(F_{1,19}=10.186, \mathrm{p}=0.005\right)$ (table 1$)$.

In both groups, all functional fitness test scores were significantly lower after six weeks of detraining than after the nine weeks of training $(\mathrm{p}<0.013)$. However, both YO and $\mathrm{O}$ groups had significantly higher chair stand scores than before training $(\mathrm{p}<0.001$ and $\mathrm{p}=0.006$ respectively $)$. In addition, in the YO group, performances on the up and go test $(p=0.003)$ and six minute walk test $(p=0.002)$ were significantly higher than before training (table 1).

Scores on the functional fitness tests declined further between six and 52 weeks of detraining. In the YO group, there were significant decreases in performances on the arm curl $(p=0.005)$, chair stand $(p=0.001)$, and six minute walk $(\mathrm{p}=0.001)$. In the $\mathrm{O}$ group, there were significant decreases in performances on the arm curl $(p=0.001)$ and chair stand $(\mathrm{p}<0.001)$.

Six minute walk $(p=0.005)$ and arm curl $(p=0.010)$ performances were significantly poorer after 52 weeks of detraining than before training in the O group, whereas all of the functional fitness tests reverted to pre-training values in the YO group (table 1).

As shown in table 2, the most pronounced effect after six weeks of detraining was in the up and go test for the YO group and in the chair stand test for the $\mathrm{O}$ group. The most pronounced effect after 52 weeks of detraining was on the arm curl in both groups. The largest between-effect sizes were observed for the up and go test after six weeks of detraining and for the arm curl and six minute walk tests after 52 weeks of detraining.

\section{DISCUSSION}

The purposes of this study were to determine the effects of short and long term detraining on functional fitness, which components of functional fitness were most affected by detraining, and whether age influenced the responses to detraining in independent living elderly people.

In both groups, performance in all of the functional fitness tests was significantly lower after six weeks of detraining than at end of the nine week training programme. However, performance in the chair stand test for both groups and in the six minute walk and up and go tests for the YO group remained significantly higher than before training after six weeks of detraining. After 52 weeks of detraining, performance in all of the functional tests had decreased to the pretraining values in both groups, except for the six minute walk and arm curl tests in the O group, which had declined below the pre-training values.

The largest between-group effect sizes were observed for the up and go test after six weeks of detraining and for the arm curl and six minute walk tests after 52 weeks of detraining. These large effect sizes suggest that the two age groups had different rates of change in agility and dynamic balance after short term detraining, and in upper extremity strength and aerobic endurance after long term detraining.

Our finding that lower extremity strength decreased after six weeks of detraining but the values remained significantly higher than those before training is consistent with previous studies of elderly people. ${ }^{46791214}$ In contrast, our finding that upper extremity strength reverted to the pre-training values in both age groups after six weeks of detraining differs from data reported by previous studies. ${ }^{71-14}$ It is difficult to explain the discrepancy between the upper and lower body response to short term detraining in this small sample. One possible explanation is that the initial training response was greater for lower extremity strength than for upper extremity strength. ${ }^{17}$ We used a shorter duration and lower intensity of training than those used in other studies ${ }^{711314}$ and our subjects may have been less physically active than in some studies. ${ }^{11}$ Detraining induced decreases in the functional performance of the neuromuscular system may be related to the frequency of the preceding training, the type and duration of the training, and the activities of daily living during the detraining period. ${ }^{911}$

These data contrast with other reports showing maintenance of training induced increases in muscular strength after 24 weeks, ${ }^{9} 27$ weeks, ${ }^{14}$ and 31 weeks ${ }^{6}{ }^{10}$ of detraining in older men. Dynamic strength generally declines after three years of detraining, although strength may remain near or slightly above pre-training levels. ${ }^{11}$ In contrast, Fiatarone et $a l^{5}$ reported a $32 \%$ loss of maximal strength after only four weeks of detraining in seven frail elderly subjects who had previously shown dramatic gains in strength after eight weeks of strength training. Another group reported that 10 weeks of detraining significantly reduced muscular performance. ${ }^{4}$ Others have reported a return to pre-training strength levels after one year of detraining ${ }^{13}$ or that strength may decline even further below pre-training levels. ${ }^{8}$ Our subjects had initial low fitness and physical activity levels, ${ }^{16} 17$ and other studies included more active ${ }^{9-11} 14$ and physically fit $^{4}{ }^{6}$ subjects and used longer training programmes. ${ }^{11}$ Thus the initial levels of physical activity and functional capacity may account in part for the declines in strength after detraining in our subjects. In addition, they had some medical problems and less mobility, as did subjects in other studies. ${ }^{458}$ A greater magnitude of strength loss is expected in elderly people with medical problems that may directly affect their physical activity patterns.

To my knowledge, the data showing that age affected the loss of aerobic endurance after short and long term detraining in elderly people is a novel finding. The YO group retained a portion of their recently acquired aerobic endurance after six weeks of detraining, although aerobic endurance declined below pre-training values in the $\mathrm{O}$ group 


\section{What is already known on this topic}

The effects of training are gradually lost when training ceases. Most studies of detraining in elderly people have focused on the effects on muscular strength, performance measures of physical function, body composition, and blood lipid concentration after the cessation of moderate to high intensity resistance training.

\section{What this study adds}

This study determined the effects of short and long term detraining on functional fitness in elderly subjects, which components of functional fitness were most affected by detraining, and whether the age of the subjects influenced the responses to detraining. It was found that changes in functional capacity after short and long term detraining are affected by age in the elderly.

after 52 weeks of detraining. Sforzo et $a l^{4}$ reported that subjects completing 16 weeks of cardiovascular exercise training did not suffer any great impairment in performance after 10 weeks of detraining. Their training period was longer and their participants were fitter and had fewer medical conditions than the present subjects. ${ }^{17}$ The different responses between our $\mathrm{YO}$ and $\mathrm{O}$ subjects may reflect different adaptive processes or the presence of disease.

Although the groups did not differ significantly, there was a large between-group effect size for the up and go test after six weeks of detraining, which suggested that agility and dynamic balance differed between the two groups after short term detraining. Functional mobility scores, measured by the timed up and go and timed $20 \mathrm{~m}$ walk tests, had declined after one year of detraining in nursing home residents. ${ }^{8}$

The effects of age on the loss of muscular strength during detraining has been investigated in only two previous studies, which compared young subjects (aged 20-30 years) with older subjects (aged 65-75 years) and found that 31 weeks of detraining caused a larger decrease in muscular strength in the older subjects. ${ }^{6}{ }^{10}$

In conclusion, six weeks of detraining did not reverse the gains in aerobic endurance and agility made during a nine week exercise programme in young-old (aged 60-73 years) adults and the gains in lower body strength of young-old and old (aged 74-86 years) elderly people. However, prolonged detraining ( 52 weeks) caused a loss of all gains made during the nine week training programme and caused a dramatic decrease in aerobic endurance in subjects 74 years of age and older. These preliminary findings await replication using a larger sample size and may provide a positive motivational force for the encouragement of continued exercise participation by older adults.

\section{ACKNOWLEDGEMENTS}

This study was supported by the Akdeniz University Research Foundation (Project Number 20.01.0122.07), the Health Science Institute, and Akdeniz University School of Physical Education and Sports. The author is grateful to Nihat Ayceman, Gülsah Sahin, Vedat Cetinkaya, and Burak Aglamıs for their motivational leadership in the testing and exercise training of our dedicated subjects.

Competing interests: none declared

\section{REFERENCES}

1 Blain H, Vuillemin A, Blain A, et al. The preventive effects of physical activity in the elderly. Presse Med 2000;29:1240-8.

2 American College of Sports Medicine Position Stand. Exercise and physical activity for older adults. Med Sci Sports Exerc 1998;30:992-1008.

3 Dudley GA, Snyder LLP. Deconditioning and bed rest: musculoskeletal response. In: Roitman JL, ed. ACSM's resource manual. Philadelphia: Lippincott Williams \& Wilkins, 1998:200-5.

4 Sforzo GA, MCManis BG, Black D, et al. Resilience to exercise detraining in healthy older adults. J Am Geriatr Soc 1995;43:209-15.

5 Fiatarone MA, Marks EC, Ryan ND, et al. High intensity strength training in nonagenarians. Effects on skeletal muscle. JAMA 1990;263:3029-34.

6 Lemmer JT, Hurlbut DE, Martel GF, et al. Age and gender responses to strength training and detraining. Med Sci Sports Exerc 2000;32:1505-12.

7 Taeffe DR, Marcus R. Dynamic muscle strength alterations to detraining and retraining in elderly men. Clin Physiol 1997;17:311-24.

8 Connely DM, Vandervoort AA. Effects of detraining on knee extensor strength and functional mobility in a group of elderly women. J Orthop Sports Phys 1997; 26:340-6.

9 Häkkinen K, Alen $M$, Kallinen $M$, et al. Neuromuscular adaptation during prolonged strength training, detraining and re-strength-training in middleaged and elderly people. Eur J Appl Physiol 2000;83:51-62.

10 Ivey FM, Tracy BL, Lemmer JT, et al. Effects of strength training and detraining on muscle quality: Age and gender comparisons. I Gerontol A Biol Sci Med Sci 2000;55:B152-9.

11 Smith K, Winegard K, Hicks AL, et al. Two years of resistance training in older men and women: the effects of three years of detraining on the retention of dynamic strength. Can J Appl Physiol 2003;28:462-74.

12 Elliott KJ, Sale C, Cable NT. Effects of resistance training and detraining on muscle strength and blood lipid profiles in postmenopausal women. $\mathrm{Br} J$ Sports Med 2002;36:340-4.

13 Porter MM, Nelson ME, Fiatarone Singh MA, et al. Effects of long-term resistance training and detraining on strength and physical activity in older women. J Aging Phys Act 2002;10:260-70.

14 Lexell J, Downham DY, Larsson Y, et al. Heavy-resistance training in older Scandinavian men and women: shortand long-term effects on arm and leg Scandinavian men and women: shortand long-ter
muscand J Med Sci Sport 1995;5:329-41.

15 Rikli RE, Jones CJ. Development and validation of a functional fitness test for community-residing older adults. J Aging Phys Act 1999;7:129-61.

16 Toraman NF, Erman A, Agyar E. Effects of multi-component training on functional fitness in older adults. J Aging Phys Act 2004;12:566-81.

17 Toraman F, Sahin G. Age responses to multicomponent training programme in older adults. Disabil Rehabil 2004;26:448-54.

18 Rikli RE, Jones CJ. Senior fitness test manual. Champaign: Human Kinetics, 2001.

18a Dixon WJ. BMDP statistical soffware manual. Oxford: University of California Press, 1992:540, 627, 1273, 1277.

19 Thomas JR, Nelson JK. Research methods in physical activity. Champaign: Human Kinetics, 1990. 